\title{
BLACK FEMINIST THOUGHT AND TRANSLATION STUDIES - INTERVIEW WITH PATRÍCIA HILL COLLINS
}

\author{
PENSAMENTO FEMIINISTA NEGRO E OS ESTUDOS DA TRADUÇÃO: \\ ENTREVISTA COM PATRÍCIA HILLS COLLINS
}

Dennys Silva-Reis [D.S-R.]: Yours would be a very important contribution to Translation Studies in Brazil and a stimulus for our work in anti-racism in the academy and in the translation field. I believe that your reflections on these topics would be very fruitful in our debates on them, given that few Black women scholars talk about these subjects.

Patricia Hill Collins [P. H. C.]: Thank you for this invitation to discuss how aspects of my work might inform Translation Studies. While I am less familiar than I would like to be with Translation Studies a field of formal study, I have thought a great deal about issues of translation within my own work. So, my answers reflect my sense of how issues of translation play out in my intellectual production.

\section{[D.S-R.]: What are the dynamics of sexism and racism through language?}

[P.H. C.]: Sexism and racism are not just ideologies but also encompass tangible social practices. As systems of power, they organize unjust social institutions and practices. In my own work, I return to the idea of community as one important site that organizes the connections between unjust social institutions and the ideological discourses that reproduce them. Community can also serve as an important site for generating antiracist and feminist analyses of social injustice. In this sense, community is a specific site where language as a set of ideas and of communicative practices occurs.

When it comes to communication and language, I further distinguish between a linguistic community and an interpretive community. A linguistic community is often seen a site of social equality where speaking a shared language ostensibly fosters similar values, ideas and a common worldview. This understanding of language itself as the bedrock linguistic communities underlies commonsense understandings of translation. Here one need only translate Portuguese into English or vice versa for

\section{Patrícia Hill Collins}

Distinguished University Professor of Sociology Emerita at the University of Maryland, College Park. Her award-winning books include Black Feminist Thought: Knowledge, Consciousness, and the Politics of Empowerment (1990, 2000) and Black Sexual Politics: African Americans, Gender, and the New Racism (2004). Her most recent book Intersectionality as Critical Social Theory is scheduled to be published in 2019.

Dennys Silva-Reis

PhD in Literature from the Universidade de Brasília (UnB). E-mail: reisdennys@gmail.com 
the members of each linguistic community to access the worldview of the other. This perspective overlooks the political implications of the terms of belonging to a particular linguistic community. In this sense, linguistic communities are apolitical - the power dynamics that affect all aspects of communication fall from view. It is adequate to plug ideas into Google Translate and see what comes out of the other end.

In contrast, my sense of an interpretive community makes power relations more central to the act of communication and translation. Power relations within an interpretive community regulate who gets to speak, who is listened to and what knowledge comes to represent that community to outsiders. Power relations shape who is silenced and who is heard. Racism and sexism work within particular linguistic communities, generating patterns of silencing and being heard that contribute to social relations of racism and sexism. Systems of power such as these turn apolitical linguistic communities into interpretive communities with differential degrees of power to speak on behalf of or represent a worldview. For example, in the United States, Black people, Latinos/as and indigenous peoples who oppose racism are routinely silenced. Similarly, when women speak out against sexual violence and sexual assault, they are disbelieved and often ridiculed. The large number of Englishspeakers in the U.S. context may constitute a linguistic community, but it is one where racism and sexism permeate values, ideas and worldview of what it means to belong to the American interpretive community. Globally, the dominance of English as the language of scholarship means that authors like me who speak, write and publish in English have access to being heard while equally if not more talented people whose work has not yet been translated into English remain relatively unknown.

In this sense, power relations among interpretive communities, with linguistic communities as the public face of an interpretive community, map on to social relations of racism, sexism and the like. Within the U.S., for example, Black people, Latinos/as, and indigenous peoples constitute interpretive communities that have long advanced counter discourses to the dominant American ideology. Relationships among interpretive communities influence why certain knowledges are legitimated whereas others remain unknown. Whether academic disciplines or nation-states, power relations shape similar patterns of silencing and being heard.

\section{[D.S-R.]: Do you see the canonical texts of the human sciences as inherently sexist and racist? Or have they simply been used that way?}

[P. H. C.]: Canonical texts within the human sciences illustrate these patterns of varying interpretive communities exercising different degrees of power in shaping what counts as knowledge. In this case, the texts are artifacts of decisions that were made at the time they were initially created and accepted, as well as the history of varying interpretive communities using them in particular ways for particular purposes. If the original written texts are sexist and racist, either via their clearly identifiable assumptions concerning race and gender or via framing assumptions that simply don't 
see race and gender as important, subsequent interpretation of those texts reinforces these ideas. For example, the canonical texts of classical sociological theory, my own discipline, simply position race and gender outside the field itself, thereby seeing them as secondary concerns. Instead, when it comes to social inequality, class constitutes the central object of investigation. In this sense, canonical texts can be racist and sexist without appearing to be so at all.

Here the idea of interpretive communities becomes especially significant. Over time, if canonical knowledge becomes decontextualized and travels as a takenfor-granted truth within a field of study, it sets the boundaries for the field. In this sense, knowledge of and acceptance of canonical texts serve as gatekeepers for who can enter that field and who cannot. Often the work performed by canonical texts in reproducing racism and sexism within a field are invisible. Canonical texts often have a lifespan with an influence that stretches far beyond their initial intent. Such texts become canonical, not exclusively due to their content, but through the power of dedicated interpretive communities (disciplines) to legitimate them as canonical texts.

When it comes to racism and sexism, in this context, the question is less whether we should read canonical texts in our respective fields but how we should read them. I find much of value in canonical texts, if I read them through the lens of a sociology of knowledge that is aware of their production and consumption. I can take what's useful and leave the rest behind. Sometimes, it is useful to criticize canonical texts, identifying the negative effects they have had in how people have taken up their ideas. In other cases, it's enough to question their utility for thinking through racism and sexism.

It honors the intellectual labor of an author to take his/her ideas seriously. But doing so requires attending to the political economy of how a text is produced. The fundamental question for any author is this -- who is your audience? As a scholar of racism and sexism who also is an author, it has been important for me to know my audiences and to distinguish among them. I read the canonical texts in my field in light of their authors and intended audiences; it matters when such texts were written, by whom, and in what political contexts. Moreover, I always give other authors the benefit of the doubt to see how effectively their texts achieve their stated purposes. Obviously, if I disagree with an author's expressed aim, e.g., a right-wing treatise on Black women's inferiority, I don't give that the benefit of the doubt. Instead, I analyze such texts to see how the author constructed his/her argument and the evidence that he/she used in support of it. This gives me insight into how to anticipate and counter such arguments, or better yet, write my own arguments in ways that already refute such work. But we also must read canonical texts that we like, critically.

When it comes to canonical texts that were created under colonialism, I think we need to think outside the canonical boxes of tradition and become authors of new traditions. For example, what will be the canonical texts of Black feminism? This field is still so new, both in the United States and in a global context that its 
contributions to anti-racist and anti-sexist inquiry and practice continue to unfold. Will such texts be texts in the traditional sense of the word? Will they be visual or oral? Can a You Tube video serve as a canonical text? The rapidly changing, networked communications framework of the web is a game changer for the ability of interpretive communities to police the boundaries of fields of study. In this sense, when it comes to racism and sexism, the days of celebrating canonical texts may be ending.

\section{[D.S-R.]: What is your sense of how sexism and racism are organized and operate in the translator/interpreter profession field?}

[P. H. C.]: I'm not sure I can speak directly to the specific issues in the field of Translation Studies. But I do think that issues that I face in doing intellectual work, especially theoretical work, illustrate how racism and sexism inform broader issues of interpretation. Because I move among so many different interpretive communities, I find myself constantly thinking about how best to say what I want to say within each community as well as what they might say to one another if direct lines of communication were available. In essence, for me, theoretical work involves constantly negotiating one set of ideas in terms of another, making sure that I am accountable to multiple communities for translations that make my work possible. For example, when it comes to Black feminist thought, since traveling to Brazil, I ask myself how I might understand and interpret the similarities and differences between Black feminism in Brazil, in the U.S., and throughout the African Diaspora?

I see my scholarship itself as a dual act of translation and interpretation. Because I am an African American woman with a particular set of educational, professional and life experiences, my work on Black women reflects this perpetual moving among interpretive communities of academia, family, and living as a Black woman in U.S. society. I see my theoretical work in Black Feminist Thought and in Black Sexual Politics as one translating one form of language into another, from everyday speech into a specialized academic language and vice versa. My book $O n$ Intellectual Activism gathers together many of the same ideas that I examine in my academic publications, making not just the ideas themselves accessible outside specialized academic language, but also the backstage thinking about doing this kind of intellectual work.

Thinking of my work as translation and interpretation among multiple interpretive communities has made two things clear. First, not all ideas translate. Some are actually untranslatable because they come from and are meaningful within particular interpretive communities. Efforts to "translate" indigenous worldviews into terms that are understandable within Western scholarship often produce caricatures of the holistic philosophies of indigenous peoples. Translating the terms of a nonWestern worldview into a Western one continues the epistemic violence that has been part of colonization. We must realize the limits of translation. 
Second, power relations influence what is seen as being worth translating and what simply doesn't exist because it hasn't been translated. Basically, some topics never come into public view because more powerful groups are simply uninterested in seeing such ideas translated. For years, there was little interest in the world view of African American women, primarily because Black women were assumed to have little of value worth saying. Fortunately, an on-going effort of Black women to speak the truth of Black women's lives changed that situation.

\section{[D.S-R.]: How might translation contribute to the dissemination of non- hegemonic feminist and anti-racist theories?}

[P. H. C.]: I'm actually more interested in the mechanisms of how we develop nonhegemonic feminist and anti-racist theories than in how we might disseminate theories that emerge from traditional ways of doing theory or theorizing. Within Western cultures, theory is highly rationed, available to a select few who manage to acquire the literacy and credentials that enable them to get theory jobs. And once within those jobs, disciplinary conventions limit what one can say and do. This is a pragmatic description of theory, one that must be taken into account with any efforts to disseminate theory that is created under these social conditions. At the same time, academic gatekeeping is eroding, creating new possibilities for more democratic ways of theorizing whereby more ideas actually get to the theory table.

That's a project that has been at the center of my attention for some time. In your questions, you quite rightly distinguish between racism and sexism. I think that we need that kind of analytical clarity, especially in analyzing how racism and sexism have been organized within different national settings. To me, they are not the same, and taking the time to learn about each is invaluable. Moving too quickly to an imagined alliance between racism and sexism under the banner of a bigger concept that erases these differences, e.g., social justice, not only is inaccurate but can be politically ineffective.

Translation studies maintain the integrity of these distinctions by requiring that scholar-activists of racism and sexism do the work of translating their ideas for audiences that typically are not their primary concern. It's different writing feminism for an assumed audience of white women than feminism for Black men. How differently anti-racist work sounds when it is written for Black audiences and white ones. Doing the work of translation sees racism and sexism as interconnected and independent, creating a pathway for seeing anti-racism and feminism as connected as well.

My work on intersectionality is very much an act of translation. I see intersectionality as a critical social theory that is less about dissemination of what has already been decided - this is the aforementioned canonical knowledge that merits criticism - but a collaborative project of constructing knowledge across differences. Translation highlight similarities but it also identifies important differences. As 
a knowledge project, intersectionality inherently rests on the foundation of good translations.

I've just finished a book titled Intersectionality as Critical Social Theory (Duke University Press, 2019) that, while I do not make translation an explicit theme, my argument rests on translation as a process for doing such theory. I spend considerable time discussing dialogical engagement as essential for building such a critical social theory that is adequate for addressing racism, sexism and broader forms of oppression. And dialogical engagement is the bedrock of translation.

\section{[D.S-R.]: In what ways do you see the act of translation as feminist and anti- racist activism?}

[P. H. C.]: Translation is never politically neutral. It's one thing to translate the language and ideas of dominant groups into terms that subordinated groups can understand. This kind of translation is accepted as business as usual. It assumes that the ideas of dominant groups are inherently worthwhile, and that translating them into terms that all others can understand is fundamentally a good idea. Activism here consists of translating documents so that Black women and similarly subordinated groups can know their rights, for example, the legal protections that may be available to them in law. Teaching can be a terrain of activism, translating texts that may not be available to one's students or helping students understand the specialized language of academia. Because so much of Western knowledge is inherently sexist and racist, working with the assumptions that underlie such knowledge and translating their canonical texts into a language that enable subordinated people to read and critically assess them can be an act of anti-racist and feminist activism.

Yet what about translating from the other side of power, namely, the ideas, analyses and knowledge produced by subordinated groups? Here, translation and activism require a different set of translation skills that are attentive to the political costs and benefits of translation. Many of us who aim to speak to, for and with people who are subordinated within intersecting systems of power engage in a more sophisticated form of translation that is context specific. Translating the ideas of women, Black people and indigenous peoples into language that dominant groups can understand may help our individual careers in the academy. But at what cost to ourselves and to the people whose ideas that we translate? The risk we run is that making certain anti-racist and feminist knowledge public may make it easier for dominant groups to manage subordinated groups. What appears to be translation as activism to make subordinated people more respectable can be a form of selling out.

I see much of my work as situated in this in-between space of translating dominant discourse into a form that is useful for social justice projects and translating the ideas of subordinate groups for one another so they can better communicate with one another. One of the more difficult tasks is to develop self-defined knowledge that enables Black women and people from similarly subordinated groups to speak with 
one another. Just as there is no one essential Black women who is typical of all, there is no one message that reflects the diverse experiences of Black women.

Creating these spaces of safe and free speech, spaces where translation need not labor across differences in power is hard. In writing Black Feminist Thought, I had to decide how much I could say about Black women's lives in public, and what should be keep private. Sometimes secrecy is essential not just to feminist and anti-racist activism, but to the very survival of Black women. It makes no sense to publicize Black women's oppositional knowledge if the increased visibility granted such knowledge increases Black women's vulnerability. Such public translations may feel activist, but they can harm Black women. It is difficult to remove assumptions of whiteness, masculinity, wealth and compulsory heterosexuality that are so central to Western discourse from honest conversations among ourselves. But we must try, hoping that by honing sophisticated skills of translation, we can craft interpretive communities that empower us. 